TERRA. Revista de Desarrollo Local e-ISSN: 2386-9968

Número 6 (2020), 356-369

DOI 10.7203/terra.6.16909

IIDL - Instituto Interuniversitario de Desarrollo Local

\title{
Reseña. ¿Lugares que no importan? La despoblación de la España rural desde 1900 hasta el presente
}

\section{Celia Losilla Casas}

Graduada en Geografía y Medio Ambiente (Universidad de Valencia, España)

locace@alumni.uv.es

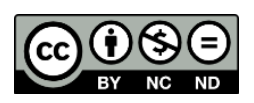

Esta obra se distribuye con la licencia Creative Commons Reconocimiento-NoComercial-SinObraDerivada 4.0 Internacional 


\section{SECCIÓN RESEÑAS}

\section{Reseña. ¿Lugares que no importan? La despoblación de la España rural desde 1900 hasta el presente}

Resumen. La obra “¿Lugares que no importan? La despoblación de la España rural desde 1900 hasta el presente" realiza un profundo análisis del fenómeno de la despoblación en el medio rural español mediante el estudio del proceso y de las diferentes cuestiones que han influido en él durante el siglo XX, con el objetivo de explicar las causas que lo provocaron, exponer la situación actual, señalar las consecuencias en el territorio y, finalmente, desmentir mitos en torno a la cuestión.

Palabras clave: Espacios rurales, espacios urbanos, demografía, agricultura, estilos de vida, problema territorial.

Recibido: 26 de marzo de 2020

Devuelto para revisión: -

Aceptado: 26 de marzo de 2020

Referencia / Citation:

Losilla, C. (2020). Reseña. ¿Lugares que no importan? La despoblación de la España rural desde 1900 hasta el presente. TERRA. Revista de Desarrollo Local, (6), 365-369. DOI 10.7203/terra.6.16909 


\section{Fernando Collantes y Vicente Pinilla}

\section{¿LUGARES QUE NO IMPORTAN? LA DESPOBLACIÓN DE LA ESPAÑA RURAL DESDE 1900 HASTA EL PRESENTE}

Monografías de Historia Rural, 15. Prensas de la Universidad de Zaragoza, 2019. 266 páginas.

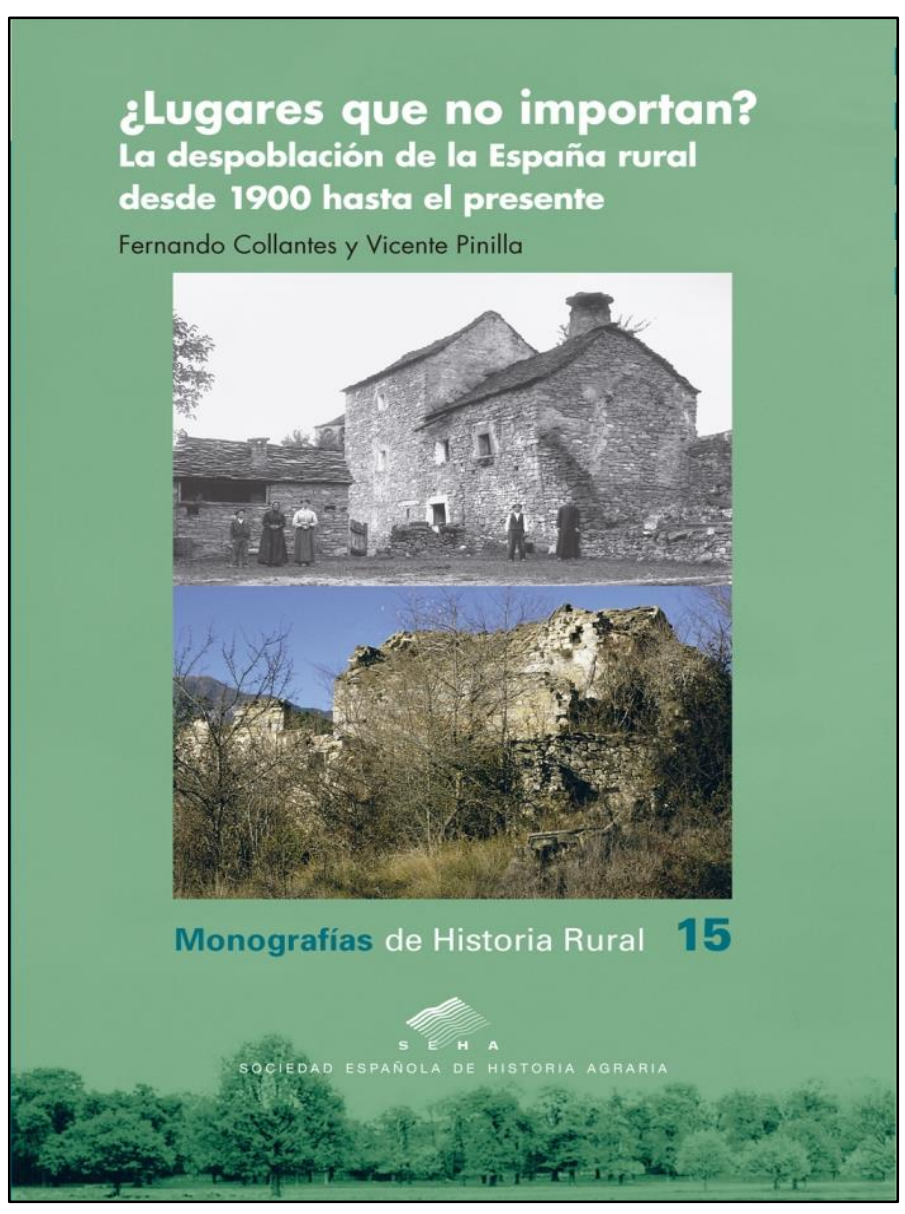

La obra "¿Lugares que no importan? La despoblación de la España rural desde 1900 hasta el presente" realiza un profundo análisis del fenómeno de la despoblación en el medio rural español mediante el estudio del proceso y de las diferentes cuestiones que han influido en él durante el siglo $\mathrm{XX}$, con el objetivo de explicar las causas que lo provocaron, exponer la situación actual, señalar las consecuencias en el territorio y, finalmente, desmentir mitos en torno a la cuestión. Fue publicada originalmente en inglés bajo el título "Peaceful Surrender: The Depopulation on Rural Spain in the Twentieth Century" en 2011, y posteriormente fue traducida al español por sus autores, Fernando Collantes y Vicente Pinilla, siendo publicada en España en el año 2019.

La obra trata la despoblación del medio rural español desde diferentes áreas, realizando un estudio de la cuestión mediante un exhaustivo recorrido histórico de la evolución del proceso durante el siglo XX, así como de diferentes aspectos que influyeron (y cómo lo hicieron) en ella. Entre ellos encontramos las transformaciones económicas que sufrió la sociedad española y el paso de una economía de base agraria a otra industrial; los cambios demográficos resultantes de ser una sociedad con una alta tasa de natalidad y joven a otra envejecida con un número de nacimientos en descenso; las modificaciones en las infraestructuras y servicios a la población, tanto en su oferta como en su distribución; los cambios sociológicos y de estilo de vida, y cómo estos influyeron en las decisiones de emigrar al medio urbano; las transformaciones territoriales, sobre cómo se distribuyó de manera desigual la población en España y qué consecuencias acarreó; y los cambios políticos experimentados a los largo del siglo XX, y que supusieron diferentes criterios en la ordenación territorial en el periodo.

En la obra también se exponen las consecuencias que ha tenido el fenómeno de la despoblación en la sociedad y en la estructura demográfica, en el territorio, en la economía y en el medio ambiente; las tendencias actuales del fenómeno; y cómo se ha 
desarrollado en proceso en la Unión Europea, destacando a su vez el papel que esta institución ha tenido en el devenir del proceso en España.

Figura 1. Índice de contenidos

Prólogo a la edición española. La eclosión del debate público sobre la despoblación . .9

Introducción

PARTE I. TRAS LA PISTA DE LA DESPOBLACIÓN RURAL

1. Tras la pista de la despoblación rural en Europa ..................................................................... 17

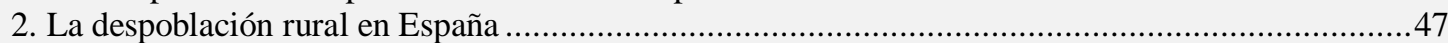

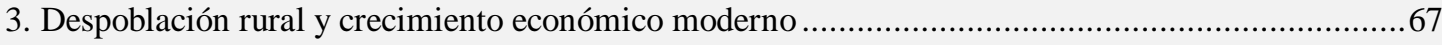

PARTE II. EXPLICANDO LA DESPOBLACIÓN

4. ¿Por qué no antes de 1950 ?

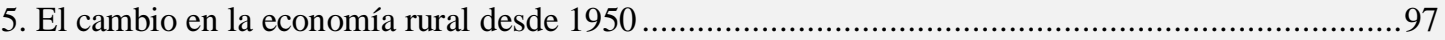

6. La penalización rural en los niveles de vida .......................................................................... 113

7. ¿Qué papel para la política? ................................................................................................ 133

PARTE III. DESPUÉS DE LA DESPOBLACIÓN

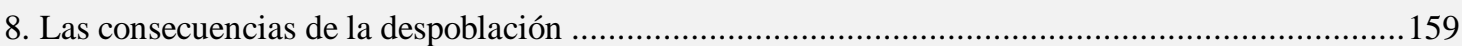

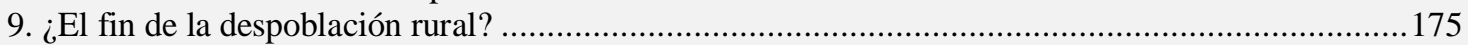

PARTE IV. CONCLUSIÓN

10. La trasformación rural española en perspectiva europea...................................................... 193

Posfacio a la edición española. Los mitos del debate público sobre la despoblación .........................213

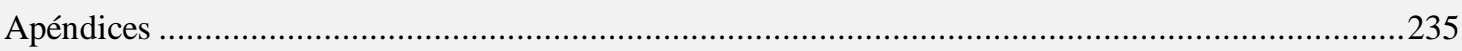

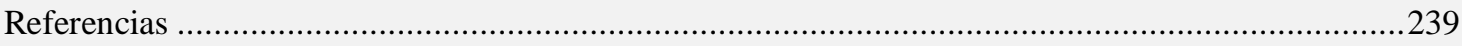

Fuente: elaboración propia.

Los autores, Fernando Collantes (profesor de Historia e Instituciones Económicas, Universidad de Zaragoza) y Vicente Pinilla (catedrático de Historia Económica, Universidad de Zaragoza), son expertos en despoblación, y su formación académica en Historia y Economía otorga una perspectiva diferente al relato, estando presente en toda la obra a través del uso de estudios y léxico de estos campos. Ambos pertenecen al Centro de Estudios sobre la Despoblación y el Desarrollo de Áreas Rurales (CEDDAR), siendo el segundo su fundador y actual director. También han sido, en distintos momentos, directores de la revista Ager (Ager. Revista de Estudios sobre Despoblación y Desarrollo Rural).

La obra se organiza mediante un prólogo de los autores, seguido de una breve introducción. Posteriormente se encuentra el cuerpo del libro, dividido en cuatro partes que, a su vez, se dividen en diferentes capítulos, y un posfacio final.

De la obra pueden destacarse diversos aspectos positivos. El más importante para nosotros es la objetividad en la exposición del tema tratado, mostrando y argumentando las ideas mediante una gran cantidad de datos elaborados en tablas, mapas y gráficos, y con una extensa revisión bibliográfica. Además, se amplía el discurso de las causas de la despoblación, hecho que contrasta con el ofrecido en muchos artículos (especialmente en 
prensa): si bien el libro ahonda en las diferentes cuestiones (tanto en aquellas más comunes en publicaciones, como por ejemplo las políticas o las demográficas, como en las menos, como los cambios en los patrones de estilo de vida y comportamiento de la población), también ofrece un análisis transversal de todas ellas, enfoque mucho más adecuado para un problema territorial como es, claramente, la despoblación. Una exposición tan amplia de evidencias ayuda a la desmitificación de ciertos aspectos del proceso, aparecidos principalmente en los medios de comunicación, y a los cuáles se dedica un apartado final. Debido a todo lo anterior, también se evita la aparición de un discurso polarizado, por lo que ni se victimiza al medio rural por las causas que han llevado al declive de estos territorios, ni se culpabiliza al medio urbano o a las políticas aplicadas de la situación del primero.

Como aspectos negativos, únicamente señalar la necesidad de un análisis regional de la despoblación en territorios más pequeños, como provinciales o supramunicipales. Si bien este no es el objetivo principal de la obra, sino un estudio en conjunto para el país (a pesar de que, a lo largo del libro, sí se realizan análisis de territorios más concretos cuando es necesario), también es cierto que los datos a nivel autonómico pueden llevar a confusión, o incluso error, al ocultar particularidades del territorio que afectan de manera decisiva al fenómeno en esas zonas.

Celia Losilla Casas

Graduada en Geografía y Medio Ambiente

Universidad de Valencia 